\title{
Prognostic significance of right ventricular afterload stress detected by echocardiography in patients with clinically suspected pulmonary embolism
}

Wolfgang Kasper, Stavros Konstantinides, Annette Geibel, Nikolaus Tiede, Thomas Krause, Hanjörg Just

\begin{abstract}
Objective-To investigate the prognostic value of echocardiographic findings in patients who present with symptoms suggestive of acute pulmonary embolism. Design-317 patients with clinically suspected pulmonary embolism were prospectively evaluated by echocardiography for the presence of right ventricular afterload stress and right heart or pulmonary artery thrombi. Objective confirmation of pulmonary embolism by lung scan or pulmonary angiography was obtained in $164(52 \%)$. The presence of deep venous thrombosis was established in 90 of 158 patients $(57 \%)$ who underwent phlebographic or Doppler sonographic studies.
\end{abstract}

Results-Right ventricular afterload stress was diagnosed in 87 patients $(27 \%)$. Objective confirmation of pulmonary embolism and diagnosis of deep venous thrombosis was more common in patients with right ventricular afterload stress than in those without $(83 \% v 40 \%$ and $46 \%$ $v 22 \%$, respectively; $P<0.001)$. This was also true for the detection of thrombi in the right heart and major pulmonary arteries (12 patients $v 1$ patient; $P<0.001$ ) as well as for the in-hospital mortality from venous thromboembolism (13\% $v$ $0.9 \%$; $P<0.001)$. One year mortality from pulmonary embolism was $13 \%$ in patients with right ventricular afterload stress at presentation compared with $1.3 \%$ in those without $(P<0.001)$.

Conclusions-The presence of right ventricular afterload stress detected by echocardiography is a major determinant of short term prognosis in patients with clinically suspected acute pulmonary embolism.

(Heart 1997;77:346-349)

Keywords: pulmonary embolism; echocardiography; right ventricular afterload stress; prognosis

Acute pulmonary embolism may be difficult to detect in routine clinical practice. ${ }^{12}$ Non-invasive procedures such as ventilation-perfusion lung scans cannot be performed at the bedside and may be associated with a disturbing degree of diagnostic uncertainty. ${ }^{3}$ On the other hand, right heart catheterisation with pulmonary angiography, generally accepted as the gold standard for diagnosis of pulmonary embolism, occasionally leads to life threatening bleeding complications in this era of thrombolytic treatment $^{4-6}$ and may not be available on a 24 hour basis in many community hospitals.

Three major factors determine the clinical presentation and course of acute pulmonary embolism: the extent of pulmonary arterial embolic obstruction, the severity of pre-existing cardiopulmonary dysfunction, and the presence of peripheral venous thrombosis as a potential threat for recurrent thromboembolic events. ${ }^{78}$ The interactions of these factors result in the development of pulmonary artery hypertension and right ventricular afterload stress, ${ }^{7}$ which can be reliably diagnosed by ultrasound imaging. ${ }^{9}$ It has been shown in previous reports that prognosis is poor when right ventricular afterload stress leads to clinically evident right heart failure (especially if accompanied by signs of cardiogenic shock)..$^{11}$ In these patients, inhospital mortality can be as high as $32 \% .{ }^{10}$ The aim of this prospective study was to test the hypothesis that echocardiographic detection of right ventricular afterload stress ${ }^{1213}$ in patients with clinically suspected acute pulmonary embolism may lead to early identification of a patient group at high risk of death or serious complications during the in-hospital phase.

\section{Methods}

During a 26 month period, 362 patients with clinical symptoms suggestive of pulmonary embolism were prospectively evaluated for the presence of pulmonary hypertension or right ventricular afterload stress, or both, as well as right sided thrombi as described previously. ${ }^{14}$ Of these, 317 patients who had complete echocardiographic studies and no evidence of significant left ventricular or mitral valve disease comprised the study group. During the study period, a physician was on call 24 hours a day to perform an echocardiographic study in patients with clinically suspected pulmonary embolism. Whenever possible, the echocardiographic examination and interpretation were performed before a further diagnostic work up was initiated. The echocardiographic study was standardised using the apical, parasternal, subcostal, and suprasternal approaches. ${ }^{12}$

A transoesophageal examination was done whenever the transthoracic examination was inconclusive. The echocardiographic diagnosis of pulmonary hypertension or right ventricular 
afterload stress was made independently of other non-invasive or invasive measurements at the patient's bedside, when either the A criterion or two of the B criteria below were fulfilled.

" $A$ " criterion-Dilatation of the right ventricular cavity (right ventricle appearing larger than the left ventricle) from the apical, subcostal, or transoesophageal four chamber view, or a right ventricular end diastolic diameter greater than $30 \mathrm{~mm}$ from the left precordial view at the level of the mitral valve apparatus.

" $B$ " criteria-(1) tricuspid regurgitation jet velocity over $2.8 \mathrm{~m} / \mathrm{s}$ as assessed by Doppler echocardiography or (2) over $2.5 \mathrm{~m} / \mathrm{s}$ in the absence of inspiratory collapse of the inferior vena cava; (3) dilatation of the right pulmonary artery ( $>12 \mathrm{~mm} / \mathrm{m}^{2}$ body surface area) on the suprasternal echocardiogram ${ }^{12}$; (4) right ventricular wall thickness over $5 \mathrm{~mm}$; (5) loss of inspiratory collapse of the inferior vena cava.

The study patients were classified as suffering from chronic right ventricular afterload stress when either of the following findings was present: (1) right ventricular wall thickness $>5 \mathrm{~mm}$; or (2) tricuspid regurgitant jet velocity $>3.7 \mathrm{~m} / \mathrm{s}$.

In case of difficulties in the interpretation of the echocardiographic findings a consensus was reached with a second observer.

Right sided pressures and cardiac output were measured by use of a balloon tipped thermodilution Swan-Ganz catheter. Pulmonary angiography was performed following injection of 30 to $40 \mathrm{ml}$ of Urografin with flow rates of 10 to $15 \mathrm{ml} / \mathrm{s}$ in each pulmonary artery using a balloon tipped side hole catheter (Berman).

Ventilation lung scans were performed with ${ }^{99 \mathrm{~m}} \mathrm{Tc} / \mathrm{MAA}$ aerosol inhalation followed by perfusion scan with intravenously injected ${ }^{99 \mathrm{~m}} \mathrm{Tc}$ DTPA in the anterior, posterior, and lateral projections. A normal or near normal lung scan was regarded as exclusion of pulmonary embolism. A high probability lung scan was defined as ventilation-perfusion mismatch of at least one lobar defect or multiple segmental defects. ${ }^{15}$ A search for deep venous thrombosis was performed either by phlebography or duplex sonography.

After hospital discharge the study patients were followed up to one year by direct telephone contact or by means of a questionnaire mailed to the patient's physician.

STATISTICAL ANALYSIS

In the statistical description of the patients,

Table 1 Diagnostic work up for pulmonary embolism and deep venous thrombosis

\begin{tabular}{llcl}
\hline & $\begin{array}{l}\text { Group } A \\
(n=87)\end{array}$ & $\begin{array}{c}\text { Group } B \\
(n=230)\end{array}$ & Pvalue \\
\hline $\begin{array}{l}\text { Age, years (SD) } \\
\text { range }\end{array}$ & $63(17)$ & $55(17)$ & $<0.01$ \\
$\begin{array}{l}\text { Sex (\%): } \\
\quad \text { Male }\end{array}$ & $(20$ to 91$)$ & $(18$ to 93$)$ & \\
$\quad$ Female & 51 & 54 & NS \\
PE confirmed & 49 & 46 & $<0.001$ \\
PE excluded & $72(83 \%)$ & $92(40 \%)$ & $<0.001$ \\
No PE work up & $2(2.3 \%)$ & $102(44 \%)$ & NS \\
DVT confirmed & $13(15 \%)$ & $36(16 \%)$ & $<0.001$ \\
DVT excluded & $40(46 \%)$ & $50(22 \%)$ & NS \\
No DVT work up & $21(24 \%)$ & $47(20 \%)$ & $<0.001$ \\
\hline
\end{tabular}

PE, pulmonary embolism; DVT, deep venous thrombosis. absolute and relative frequencies were calculated for discrete variables; means (SD) were determined for continuous variables. Differences between the characteristics of the two patient groups were tested for significance with Fisher's exact test for discrete variables, and with the Student's $t$ test for independent means for continuous variables. All tests of significance were two tailed, with $P$ values of less than 0.05 assumed to indicate statistical significance.

\section{Results}

DIAGNOSTIC WORK UP

All patients $(n=317)$ were studied echocardiographically. Transoesophageal echocardiography was required in 19 patients $(6 \%)$ in whom transthoracic imaging could neither exclude nor confirm the presence of right ventricular afterload stress. A ventilation-perfusion lung scan was performed in 235 patients (74\%) and pulmonary angiography in $67(21 \%)$. Right heart pressures were obtained invasively in 58 patients $(18 \%)$. A search for deep venous thrombosis was performed in 158 patients $(50 \%)$, either using the Doppler technique $(n=53)$ or phlebography $(n=134)$. In 49 patients there was no further diagnostic work up for pulmonary embolism after the initial echocardiographic study (table 1).

\section{PULMONARY EMBOLISM}

Confirmation of pulmonary thromboembolism by imaging studies (pulmonary angiography or a high probability lung scan) was obtained in 164 patients $(52 \%)$. In another 13 patients, the diagnosis of pulmonary embolism was related to an echocardiographic pattern of right ventricular afterload stress according to the above criteria, with confirmation of precapillary pulmonary hypertension on right heart catheterisation in nine of these patients. Clinical suspicion of pulmonary embolism was rejected in 104 patients (33\%). Deep vein thrombosis was confirmed in 90 patients (28\%) and excluded in 68 (22\%; table 1$)$.

\section{RIGHT VENTRICULAR AFTERLOAD STRESS}

According to the predefined criteria, 87 patients $(27 \%)$ presented with right ventricular afterload stress (group A), while 230 patients (73\%) had a normal echocardiogram (group B; table 1). In group A, 51 patients had signs of acute right ventricular afterload stress; whereas chronic right ventricular afterload stress was present in the remaining 36 patients. Objective confirmation of pulmonary embolism was more likely to be obtained in the patients with right ventricular afterload stress than in those without $(82 \% v 40 \%)$ as was deep venous thrombosis $(46 \% \vee 22 \% ; \mathrm{P}<0.001)$. Right sided thrombi were also more commonly observed in patients with right ventricular afterload stress (12 patients $v 1$ patient; $\mathrm{P}<0.01$ ).

\section{IN-HOSPITAL COURSE}

Total mortality and mortality related to venous thromboembolism was higher in patients with right ventricular afterload stress than in those without $(19 \% v 5.7 \%$ and $13 \% v$ 
Table 2 In-hospital course and one year follow up of patients with clinically suspected pulmonary embolism

\begin{tabular}{|c|c|c|c|}
\hline & $\begin{array}{l}\text { Group A } \\
(n=87)\end{array}$ & $\begin{array}{l}\text { Group B } \\
(n=230)\end{array}$ & $P$ value \\
\hline \multicolumn{4}{|l|}{ In-hospital events: } \\
\hline Total mortality & $16(18 \cdot 4 \%)$ & $13(5 \cdot 7 \%)$ & $<0.001$ \\
\hline Mortality due to PE & $11(12 \cdot 6 \%)$ & $2(0.9 \%)$ & $<0.001$ \\
\hline Cardiopulmonary resuscitation & $16(18 \cdot 4 \%)$ & $5(2 \cdot 1 \%)$ & $<0.001$ \\
\hline \multicolumn{4}{|l|}{ Treatment during acute phase: } \\
\hline Thrombolytics & $37(42 \cdot 5 \%)$ & $12(5 \cdot 2 \%)$ & $<0.001$ \\
\hline Heparin anticoagulation & $43(49 \cdot 4 \%)$ & $159(69 \cdot 1 \%)$ & $<0.001$ \\
\hline Surgical embolectomy & $5(5 \cdot 8 \%)$ & 0 & $<0.001$ \\
\hline Caval filter implantation & $7(8 \cdot 1 \%)$ & $5(2 \cdot 2 \%)$ & 0.02 \\
\hline Catecholamines & $17(19 \cdot 5 \%)$ & $6(2 \cdot 6 \%)$ & $<0.001$ \\
\hline No specific treatment & $2(2 \cdot 3 \%)$ & $59(25 \cdot 7 \%)$ & $<0.001$ \\
\hline One year mortality due to PE & $11(12 \cdot 6 \%)$ & $3(1 \cdot 3 \%)$ & $<0.001$ \\
\hline
\end{tabular}

$0.9 \%$, respectively; $\mathrm{P}<0.001)$. Likewise, cardiopulmonary resuscitation was more often required in patients of group $\mathrm{A}$.

Aggressive treatment such as thrombolysis, surgical embolectomy, implantation of a caval filter, or need for catecholamines was also more often required for patients in group A than for those in group B (table 2).

\section{ONE YEAR FOLLOW UP}

During one year of follow up after hospital discharge, only one patient in group B died from consequences of venous thromboembolism (table 2).

\section{Discussion \\ NATURAL HISTORY OF VENOUS \\ THROMBOEMBOLISM}

A complete five year survey of necropsy data 30 years apart revealed that the incidence of venous thromboembolism as a cause or contributing factor of death in hospital inpatients is nearly unchanged. ${ }^{16}$ We still know little about the natural history of venous thromboembolism. ${ }^{17}$ The risks and benefits of different treatment strategies are also unclear. ${ }^{3}$ Some prospective trials of patients with clinically suspected pulmonary embolism included only haemodynamically stable patients who had to undergo a battery of diagnostic tests to confirm or exclude pulmonary embolism. ${ }^{15} 18$ Other studies dealing with the management of deep vein thrombosis and pulmonary thromboembolism also excluded patients who had either an inadequate cardiopulmonary reserve $^{8}$ or the clinical presentation of a life threatening disease. ${ }^{19} 20$ Taken together, these studies suggest that stable patients with pulmonary embolism may have a benign clinical course, the rate of fatal thromboembolic events being as low as $1 \% .{ }^{820}$

\section{MORTALITY AND RIGHT VENTRICULAR} AFTERLOAD STRESS

In the present study we showed that, in patients with clinically suspected acute pulmonary embolism, in-hospital mortality and the rate of serious complications strongly correlated with the presence of right ventricular afterload stress detected by echocardiography. This association was even more pronounced when only death secondary to venous thromboembolism was considered. Patients who presented with acute right ventricular afterload stress did even worse: 12 of 51 patients died $(23.5 \%)$, compared with four of 36 patients with chronic right ventricular afterload stress (11\%). In addition, patients with echocardiographically detected right heart or pulmonary artery thrombi had an unfavourable in-hospital course, with death in six of 13 patients. The majority of the patients in the group with right ventricular afterload stress ( 32 of 37 ) received thrombolysis because of pulmonary embolism, as opposed to only one patient in group B.

On the other hand, patients without right ventricular afterload stress had a benign inhospital course, irrespective of whether pulmonary embolism was confirmed or excluded by further diagnostic work up. After hospital discharge, one year's clinical follow up revealed that only one patient in this group died of venous thromboembolism. Thus mortality from venous thromboembolism seems to be mainly determined by the acute haemodynamic consequences of pulmonary embolism.

ECHOCARDIOGRAPHY FOR SUSPECTED PULMONARY EMBOLISM

The approach in this study for patients with clinically suspected pulmonary embolism was different from that of previous series, ${ }^{819}$ placing primary emphasis on the haemodynamic results of a clinically suspected pulmonary thromboembolic event. It has already been shown that the haemodynamic effects of pulmonary emboli can reliably be detected by the use of echocardiography. ${ }^{9} 1321$ Furthermore, several other cardiovascular diseases which may be clinically confused with pulmonary embolism can be diagnosed or excluded by an echocardiographic examination. An additional advantage is the bedside availability of echocardiography, which makes it a safe procedure for critically ill patients or for those who cannot be easily transported.

Some limitations of echocardiography should be kept in mind, especially with respect to the diagnostic work up of patients with suspected pulmonary embolism. Some of the echocardiographic changes observed in patients with pulmonary embolism may also occur in other clinical situations such as right ventricular myocardial infarction, ${ }^{22}{ }^{23}$ sarcoidosis of the heart, ${ }^{24}$ congenital heart disease,${ }^{25}$ or previous pulmonary disease..$^{26}$ Furthermore, in patients with significant left heart disease, echocardiographic and Doppler studies are unable to assess the haemodynamic consequences of pulmonary embolism because right ventricular afterload stress may be related primarily to the underlying cardiovascular disease (postcapillary pulmonary hypertension) and not to the consequences of venous thromboembolism.

\section{CONCLUSIONS}

The following conclusions can be drawn from our study. (1) Patients with clinically suspected pulmonary embolism have a poor prognosis if they present with right ventricular afterload stress as assessed by echocardiography. (2) In the absence of right ventricular afterload stress these patients generally have a 
good prognosis. (3) This seems to be true irrespective of documented pulmonary embolism by angiography or nuclear imaging methods.

Therefore, invasive diagnostic methods may not be immediately necessary in patients with clinically suspected pulmonary embolism in whom right ventricular afterload stress can be excluded echocardiographically. This policy may allow a more reasonable and economical approach with regard to further diagnostic and therapeutic procedures in those patients. Aggressive therapeutic strategies may be of little, if any, benefit for patients with pulmonary embolism who do not suffer from right ventricular afterload stress as assessed by echocardiography.

We are indebted to $\mathrm{M}$ Olschewski $\mathrm{PhD}$ for performing the statistical analysis.

1 Goldhaber SZ, Hennekens CH, Evans DH, Neuton EC, Godleski JJ. Factors associated with correct antemortem diagnosis of major pulmonary embolism. $\mathrm{Am} \mathcal{f} \mathrm{Med}$

2 Hull RD, Raskob GE, Hirsh J. The diagnosis of clinically suspected pulmonary embolism. Chest 1989;80:417S $25 S$.

3 Kelley MA, Carson JL, Palevsky HI, Schwartz S. Diagnosing pulmonary embolism: new facts and strategies. Ann Intern Med 1991;114:300-6.

4 Meyer G, Sors H, Charbonnier B, Kasper W, Bassand JP, Kerr IH, et al. Effect of intravenous urokinase versus alteplase on total pulmonary resistance in acute massive alteplase on total pulmonary resistance in acute massive pulmonary embolism: a European multicenter

5 Dalla-Volta S, Palla A, Santolicandro A, Giuntini C, Pengo V, Visioli O, et al. PAIMS 2: alteplase combined with heparin versus heparin in the treatment of pulmonary embolism. Plasminogen Activator Italian Multicenter Study 2. $\mathcal{F}$ Am Coll Cardiol 1992;20:520-6.

6 Stein PD, Hull RD, Raskob G. Risks of major bleeding from thrombolytic therapy in patients with acute pulfrom thrombolytic therapy in patients with acute $p$

7 McIntyre KM, Sasahara AA. Haemodynamic and ventricular response to pulmonary embolism. Progr Cardiovasc

Dis 1974;17:175-90.
8 Hull RD, Raskob GE, Coates G, Panja AA, Gill GJ. A new noninvasive management strategy for patients with suspected pulmonary embolism. Arch Intern Med 1989;149: 2549-55.

9 Kasper W, Geibel A, Tiede N, Bassenge D, Kauder E, Konstantinides S, et al. Distinguishing between acute and subacute massive pulmonary embolism by conventional and Doppler echocardiography. $B r$ Heart $f$ 1993;70: 352-6.

10 Alpert JS, Smith R, Carlson J, Ockene IS, Dexter L, Dalen JE. Mortality in patients treated for pulmonary embolism fAMA 1976;236:1477-80.

11 Hall RJC, Sutton GC, Kerr IH. Long-term prognosis of treated acute massive pulmonary embolism. Br Heart $\mathfrak{f}$ 1977;39:1128-34.

12 Kasper W, Meinertz T, Kersting F, Lang K, Limbourg P, Just $H$. Echocardiography in assessing acute pulmonary hypertension due to pulmonary embolism. Am $f$ Cardiol 1980;45:567-72.

13 Kasper W, Meinertz T, Henkel B, Eissner D, Hahn K, Hofmann $\mathrm{T}$, et al. Echocardiographic findings in patients with pulmonary embolism. Am Heart $\mathcal{f} 1986 ; 112: 1284-90$.

14 Kasper W, Geibel A, Tiede N, Just H. Patent forame ovale in patients with haemodynamically significant pulmonary embolism. Lancet 1992;340:561-4.

15 The PIOPED Investigators. Value of the ventilation/perfusion scan in acute pulmonary embolism. $\mathcal{F} A M A 1990$ 263:2753-9.

16 Lindblad B, Sternby NH, Bergquist D. Incidence of venous thrombo-embolism verified by necropsy over 30 years. BMF 1991;302:709-11.

17 Robin ED. Overdiagnosis and overtreatment of pulmonary embolism. The emperor may have no clothes. Ann Intern Med 1977;87:775-81.

18 Hull RD, Hirsh J, Carter CJ, Jay RM, Dodd PE, Ockeford $\mathrm{PA}$, et al. Pulmonary angiography, ventilation lung scanning and venography for clinically suspected pulmonary embolism with abnormal perfusion lung scan. Ann Intern Med 1983;98:891-9.

19 Kruit WHJ, De Boer AC, Sing AK, van Roon F. The significance of venography in the management of patients with clinically suspected pulmonary embolism. $\mathcal{F}$ Intern Med 1991;230:333-9.

20 Research Committee of the British Throacic Society Optimum duration of anticoagulation for deep vein thrombosis and pulmonary embolism. Lancet 1992, 340:873-6.

21 Wolfe MW, Lee RT, Feldstein ML, Parker JA, Come PC, Goldhaber SZ. Prognostic significance of right ventricular hypokinesis and perfusion lung scan defects in pulmonary embolism. Am Heart J 1994;127:1371-5.

22 Lopez-Sendon J, Garcia-Fernandez MA, Coma-Canella I, Yanguela MM. Banuelos F. Segmental right ventricular Yanguela MM. Banuelos F. Segmental right ventricular fional echocardiographic study in 63 patients. $A m f$ Cardiol 1983;51:390-6.

23 Goldberger JJ, Himelman RB, Wolfe CL, Schiller NB. Right ventricular infarction: recognition and assessment Right ventricular infarction: recognition and assessment
of its haemodynamic significance by two-dimensional echocardiography. F Am Soc Echocardiogr 1991;4:140-6.

24 Lewin RF, Mor R, Spitzer S, Arditti A, Helman C, Agmon J. Echocardiographic evaluation of patients with systemic sarcoidosis. Am Heart f 1985;10:116-22.

25 Feneley M, Gavaghan T. Paradoxical and pseudoparadoxical inter-ventricular septal motion in patients with righ ventricular volume overload. Circulation 1986;74:230-8.

26 Himelman RG, Struve SN, Brown JK, Naumum $P$ Schiller NB. Improved recognition for cor pulmonale in patients with severe chronic obstructive pulmonary disease. $A m$ f Med 1988;84:891-8. 